\title{
A responsabilidade penal por infração de deveres especiais em relação aos funcionários públicos: análise de caso nos autos das ações penais da Operação "Lava-Jato"
}

\section{Criminal liability for violation of special duties of civil servants: case analysis in the criminal proceedings of Operation "Car Wash"}

Ana Beatriz Cruz Nunes ${ }^{1}$.

Patrícia Borba Marchetto².

\begin{abstract}
RESUMO: Nos últimos anos, no âmbito dos estudos sobre direito penal na América Latina, tem sido recorrente o debate sobre a ampliação do conceito de funcionário público, não apenas no âmbito normativo e doutrinário, mas, especialmente, no âmbito jurisprudencial. Com a deflagração das denúncias de corrupção ativa, corrupção passiva e lavagem de dinheiro pelo Ministério Público Federal no esquema de corrupção envolvendo a Petrobras, funcionários públicos de alto escalão e executivos de grandes empreiteiras, popularmente conhecido como Operação "Lava-Jato", tal debate assumiu contornos relevantes em razão da notoriedade do caso. Ante a complexidade do caso, as decisões judiciais envolvendo a Operação "Lava-Jato" abordaram diversas questões sensíveis ao estudo dogmático do delito de corrupção passiva. Assim, o presente artigo buscará analisar as modificações jurisprudenciais sobre os critérios de imputação do delito de corrupção passiva na atualidade, bem como da compreensão do conceito de funcionário público. Para tal, serão realizadas as análises normativa (a partir dos métodos dedutivo, indutivo, comparativo e dialético), dogmática (partir do método funcionalista sistêmico) e de caso (através dos métodos dedutivo e indutivo). Ao final, será realizada a projeção da dogmática penal funcionalista sistêmica sobre os critérios de imputação da responsabilidade por dever especial do funcionário público no âmbito do delito de corrupção passiva.
\end{abstract}

1 Bacharela e Mestranda em Direito pela Faculdade de Ciências Humanas e Sociais (FCHS) da UNESP, Campus de Franca/SP. Projeto de Pesquisa de Mestrado financiado pela Coordenação de Aperfeiçoamento de Pessoal de Nível Superior (CAPES). E-mail: ana_nunes@yahoo.com.br.

2 Doutora em Direito pela Universidade de Barcelona, com título reconhecido pela Faculdade de Direito da USP, docente do Departamento de Administração Pública da Faculdade de Ciências e Letras (FCLAR) da UNESP, Campus de Araraquara/SP e do Programa de Pós Graduação em Direito da Faculdade de Ciências Humanas e Sociais (FCHS) da UNESP, Campus de Franca/SP. E-mail: patricia.marchetto@unesp.br. 
Palavras-chave: funcionário público, Operação "Lava-Jato", responsabilidade penal por deveres especiais.

ABSTRACT: In recent years, in the field of criminal law studies in Latin America, has been recurring the debate about the enlargement of the civil servant or public agent concept, not only in the normative and doctrinal scope, but especially in case law. With the outbreak of allegations of active corruption, passive corruption and money laundering by the Federal Prosecution Service in the corruption scheme involving Petrobras, senior civil servants and executives of major contractors, popularly known as Operation "Car Wash", such debate assumed relevant outlines due to the notoriety of the case. Given the complexity of the case, court decisions involving Operation "Car Wash" approached several sensitive issues to the dogmatic study of the crime of passive corruption. Thus, this paper will seek to analyze the jurisprudential changes on corruption imputation criteria nowadays, as well as the concept of civil servant has changed. For this, will be performed the normative (from deductive, inductive, comparative and dialectical methods), dogmatic (from the systemic functionalism method) and case (through deductive and inductive methods) studies. Lastly, will be held the systemic functionalist criminal dogmatics projection of the criteria of criminal liability for special duties imputation in the face of civil servants in the scope of passive corruption crime.

Keywords: civil servant, Operation "Car Wash", criminal liability for special duties.

\section{Introdução}

Notadamente, na sociedade contemporânea, visualiza-se uma forte tendência de ampliação das situações em que o direito penal é chamado a intervir, seja na introdução de novos tipos penais, como nos exemplos de novos interesses coletivos relacionados ao meio ambiente, à ordem econômica e financeira ou à ordem consumerista; seja no agravamento dos interesses já existentes, dentro de uma perspectiva de re-valoração dos mesmos; ou na reinterpretação das garantias clássicas do direito penal ${ }^{3}$ (SILVA SÁNCHEZ, 2001). De fato,

3 Silva Sánchez (2001) destaca como algumas das causas dessa tendência de expansão do Direito Penal: o surgimento de novos interesses ou de novas valorações de interesses pré-existentes (especialmente em relação aos bens coletivos e aos interesses difusos); o surgimento de novos riscos (característico da sociedade pós-industrial marcada pela racionalidade econômica fortemente instável e variante, bem como pelo surgimento de avanços científicos e tecnológicos sem precedentes históricos); a institucionalização da insegurança (pois, em sua concepção, a sociedade pós-industrial é a sociedade do risco, convertendo-se em uma sociedade da insegurança) com a consequente ampliação da sensação de insegurança; a configuração de uma sociedade de sujeitos passivos (tanto no sentido de restrição das esferas de atuação desses sujeitos, como também no sentido de baixa tolerância psicológica aos riscos e perigos da sociedade pós-industrial dentro do que o autor compreende como protótipo da vítima que sempre busca um terceiro responsável por seus infortúnios), desdobrando-se na identificação social com a vítima em detrimento do autor; o descrédito das instituições de proteção e responsabilização civil com a incremento da visão do direito penal como único instrumento eficaz de pedagogia político-social; descrença nos gestores da nova moral coletiva (em grande medida pela crítica político-ideológica dos movimentos de esquerda e pela ascensão da política criminal social-democrata europeia); e do gerencialismo (compreendido como a 
verifica-se que nas últimas três décadas o Estado brasileiro tem se alinhado a essa tendência, especialmente no que se refere à ampliação da tutela penal em relação a questões que envolvem o meio ambiente, às relações de consumo e a ordem econômica.

Tal expansão não necessariamente implica em prejuízo ao interesse social, pois, com efeito, com a intensificação da complexidade das estruturas sociais, no âmbito da sociedade do risco, altamente vinculada à racionalidade econômica e globalizada, a dogmática jurídico-penal é instada a ampliar seus espaços de intervenção jurídico-penal. Portanto, é possível afirmar que, em certa medida, a expansão do direito penal corresponde às demandas de tutela penal de uma sociedade complexa (SILVA SÁNCHEZ, 2001).

Portanto, como reflexo desse processo de ampliação do direito penal, verifica-se a ampliação da demanda social por maior proteção a canalizar-se "en términos más o menos irracionales como demanda de punición”" (SILVA SÁNCHEZ, 2001, p.22). Nesse sentido, fazse mister a canalização e a introdução de elementos de racionalização dessa expansão do direito penal. Ou seja,

\begin{abstract}
puede afirmarse que ciertamente existe, como se indicara al principio, un espacio de expansión razonable del Derecho penal. (...) En este ámbito, además, la razonabilidad de la expansión requeriría la plena salvaguarda de todos los criterios clássicos de imputación y principios de garantía. (...) En la medida en que esta exigencia no es respetada por los ordenamientos jurídicos de nuestro entorno, por el momento, la expansión del Derecho penal carece, en mi opinión, de la requerida razonabilidad político-jurídica. (SILVA SÁNCHEZ, 2001, p. 162).
\end{abstract}

Contudo, na contramão dos aportes sinalizados por Silva Sánchez (2001), também visualiza-se no sistema jurídico brasileiro a expansão do Direito Penal no sentido prejudicial ao interesse social, na medida em que passa a atuar fora do âmbito jurídico-normativo e dogmático, deixando de abordar as razões jurídicas dos fenômenos observados. É possível perceber tal problema especialmente na análise da imputação da responsabilidade penal nos delitos de corrupção passiva no que se refere à ampliação do conceito de funcionário público.

No âmbito administrativo, funcionário público é toda pessoa ligada à máquina pública, podendo ser responsabilizado no âmbito administrativo, civil e penal. No âmbito penal, o

ampliação da gestão eficiente de determinados problemas sem sua conexão com valores, levando a diminuição da eficácia preventiva e ao incremento da sanção). Segundo o autor, a globalização influencia nos referidos processos potencializando e multiplicando a expansão do direito penal. 
conceito de funcionário público está disposto no artigo 327 do Código Penal. As convenções internacionais sobre o enfrentamento à corrupção das quais o Estado brasileiro é signatário também trataram de definir o conceito de funcionário público. O que é inconteste no âmbito doutrinário e dogmático é que a função pública guarda deveres especiais, deveres estes que são inerentes à função e ao rol social desempenhado pela pessoa que a ocupa. Nesse sentido, o crime de corrupção é considerado um crime próprio, caracterizado pela ação ou omissão de determinadas pessoas legalmente especificadas.

Atualmente tem-se destacado a ampliação do conceito de funcionário público especialmente no âmbito penal, trazendo à tona a discussão acerca dos limites da imputação penal, especialmente nos delitos de corrupção passiva. Com isso, faz-se necessária a discussão acerca do impacto dessa ampliação na responsabilização penal enquanto funcionário público nos delitos de corrupção passiva e em que medida essa tendência acompanha as exigências do direito penal na atualidade.

Assim, no presente trabalho, buscar-se-á analisar os critérios normativos e dogmáticos do crime de corrupção passiva numa perspectiva funcionalista sistêmica analisando-se ampliação do conceito de funcionário público a partir do estudo das denúncias de corrupção passiva contra ex-funcionários públicos do alto escalão da Petrobras e do Poder Executivo, nos autos dos processos $n^{\circ}$ 5051379-67.2015.4.04.7000 e $\mathrm{n}^{\circ}$ 5021365-32.2017.404.7000, ambas oferecidas pelo Ministério Público Federal e disponíveis para consulta no site do referido Órgão Público. Será analisada, ainda, a sentença condenatória dos últimos autos.

A escolha do case se deu em razão da atualidade e da relevância pública das denúncias ofertadas e da decisão judicial do case para a compreensão das modificações jurisprudenciais sobre os critérios de imputação do delito de corrupção passiva na atualidade.

A análise normativa será realizada a partir dos métodos dedutivo, indutivo, comparativo e dialético; a análise dogmática será realizada à partir do método funcionalista sistêmico e, por fim, a análise do case será realizada através dos métodos dedutivo e indutivo.

Ao final, será realizada a projeção da dogmática penal funcionalista sistêmica sobre os critérios de imputação da responsabilidade por dever especial do funcionário público no âmbito do delito de corrupção passiva, como uma ferramenta para a limitação da intervenção penal, 
visando a proteção da ordem jurídica, dos interesses da sociedade e, principalmente, da proteção dos direitos humanos fundamentais.

\section{Aportes jurídico-normativos e dogmáticos sobre o crime de corrupção passiva}

Os delitos de corrupção estão relacionados com os interesses de toda a sociedade e dos seus cidadão, assim, seu enfrentamento é fundamental para a efetivação da cidadania e dos direitos humanos fundamentais. A relevância do combate à corrupção levou a comunidade internacional à aprovação das Convenções da Organização para a Cooperação Econômica e Desenvolvimento $(\mathrm{OCDE})^{4}$ e da Organização dos Estados Americanos (OEA $)^{5}$, bem como, mais recentemente, as Convenções de Mérida ${ }^{6}$ e de Palermo ${ }^{7}$.

A Convenção Interamericana contra a Corrupção (OEA) define, em seu artigo VI, como atos de corrupção:

a. a solicitação ou a aceitação, direta ou indiretamente, por um funcionário público ou pessoa que exerça funções públicas, de qualquer objeto de valor pecuniário ou de outros benefícios como dádivas, favores, promessas ou vantagens para si mesmo ou para outra pessoa ou entidade em troca da realização ou omissão de qualquer ato no exercício de suas funções públicas;

b. a oferta ou outorga, direta ou indiretamente, a um funcionário público ou pessoa que exerça funções públicas, de qualquer objeto de valor pecuniário ou de outros benefícios como dádivas, favores, promessas ou vantagens a esse funcionário público ou outra pessoa ou entidade em troca da realização ou omissão de qualquer ato no exercício de suas funções públicas;

c. a realização, por parte de um funcionário público ou pessoa que exerça funções públicas, de qualquer ato ou omissão no exercício de suas funções, a fim de obter ilicitamente benefícios para si mesmo ou para um terceiro;

d. o aproveitamento doloso ou a ocultação de bens provenientes de qualquer dos atos a que se refere este artigo; e

4 Conhecida como Convenção sobre o Combate da Corrupção de Funcionários Públicos Estrangeiros em Transações Comerciais Internacionais, foi firmada em 17 de dezembro de 1997 pelos Estados membros, juntamente à Argentina, Brasil, Bulgária, Chile e República Eslovaca, tendo entrado em vigor no ano de 1999. No Brasil, a Convenção foi ratificada em 15 de junho de 2000 e promulgada pelo Decreto Presidencial no 3.678 , de 30 de novembro de 2000.

5 Conhecida como Convenção Interamericana contra a Corrupção, foi firmada em 29 de março de 1996, em Caracas, Venezuela. No Brasil, foi aprovada pelo Decreto Legislativo $\mathrm{n}^{\circ} 152$, de 25 de junho de 2002 e promulgada pelo Decreto Presidencial no 4.410, de 7 de outubro de 2002.

6 Conhecida como Convenção das Nações Unidas contra a Corrupção, foi adotada pela Assembléia-Geral das Nações Unidas em 31 de outubro de 2003 e assinada pelo Brasil em 9 de dezembro de 2003, tendo sido promulgada pelo Decreto $\mathrm{n}^{\mathrm{o}} 5.687$, de 31 de janeiro de 2006.

7 Conhecida como Convenção das Nações Unidas contra o Crime Organizado Transnacional, promulgada pelo Decreto $\mathrm{n}^{\mathrm{0}} 5.015$, de 12 de março de 2004. 
e. a participação, como autor, co-autor, instigador, cúmplice, acobertador ou mediante qualquer outro modo na perpetração, na tentativa de perpetração ou na associação ou confabulação para perpetrar qualquer dos atos a que se refere este artigo.

No ordenamento jurídico brasileiro, os delitos de corrupção ativa ou passiva encontramse disciplinados no Título XI "Dos crimes contra a administração pública" do Código Penal brasileiro. Segundo o entendimento doutrinário, são delito próprios e formais, ou seja, que não necessitam de um resultado naturalístico para sua configuração. Segundo a definição doutrinária, crimes próprios são aqueles delitos que não podem ser cometidos por qualquer pessoa, pois exige uma qualidade pessoal do agente ou, em outras palavras, somente podem ser cometidos por aquele que desempenha determinada função, seja o tutor, o médico, o empregador ou o funcionário público, por exemplo. Nos crimes próprios, a conduta prevista é sempre omissiva, ou seja, prevê uma inação (BITENCOURT, 2016).

No caso dos funcionários públicos, existe um rol de condutas penalmente relevantes que somente podem ser realizadas por estes e que estão descritas no Capítulo I do Título XI do Código Penal. Em razão de sua ocupação profissional, o funcionário público exerce funções específicas com direitos e deveres próprios e responsabilidades determinadas em lei, as quais devem ser cumpridas para o exercício harmônico dos serviços públicos e para o atendimento das expectativas sociais. Seu papel, ou rol de funções, é moldado a partir de seus deveres especiais de modo que somente poderá atuar com liberdade dentro daquilo que lhe é permitido em lei.

O caput do artigo 317 do Código Penal tipifica como corrupção passiva a solicitação, o recebimento ou o aceite de vantagem indevida, direta ou indiretamente, em razão da função pública, ainda que fora ou antes de assumí-la. Por se tratarem de delitos formais tendo como núcleo do tipo os verbos solicitar (no delito de corrupção passiva, artigo 317 do Código Penal) e oferecer (no delito de corrupção ativa, artigo 333 do Código Penal), o simples fato da existência de uma promessa advinda de um funcionário público para um particular (no caso da corrupção passiva) ou de um particular para um funcionário público (no caso da corrupção ativa) é suficiente para a caracterização do delito de corrupção, não sendo necessária infração do dever de ofício pelo agente público, pois ambos os delitos não exigem resultado naturalístico. Ademais, a forma culposa não é admitida, fazendo-se necessária para a configuração do delito a comprovação do dolo, ou seja, da intencionalidade da prática delitiva ou a confirmação de 
que a vontade do agente está maculada (BITENCOURT, 2016).

Evidentemente, o caput do artigo 317 do Código Penal trata de vantagem indevida recebida, solicitada ou aceita por funcionário público em decorrência de sua função, mesmo que fora dela ou antes de assumi-la. A prática ou não do ato de ofício é mero exaurimento, pois o tipo se aperfeiçoa com a solicitação, recebimento ou aceitação da vantagem indevida. Nesse sentido, para a comprovação da autoria e materialidade que ensejam a intervenção penal é necessário demonstrar que a "ação traduza 'comércio' da função, isto é, deve existir mercancia da função pública" (BITENCOURT, 2016, p. 114). Insta esclarecer, ainda, que

\begin{abstract}
A proibição contida no art. 333 incrimina a conduta de "oferecer ou prometer vantagem indevida para que e faça o deixe de fazer- itálico", e não "porque fez ou deixou de fazer", que são coisas completamente diferentes; nos termos da previsão legal, constitui corrupção ativa "oferecer ou prometer vantagem indevida a funcionário público, para determiná-lo a praticar, omitir ou retardar ato de ofício". Pode-se até discordar da desarmonia do texto legal e do paralelismo que, teoricamente, deveria existir entre as figuras ativa e passiva, mas isso não nos autoriza a ignorar os princípios da reserva legal e da tipicidade estrita, e insistir na equivalência de figuras distintas significa adotar analogia de normas incriminadoras, inadmissível em direito penal (BITENCOURT, 2016, p. 115).
\end{abstract}

Assim, como ensina Muñoz Conde (2004, p. 1004, apud BITENCOURT, 2016, p. 119), "não se trata, portanto, de um crime bilateral, no sentido de que o delito surge como aperfeiçoamento de um acordo de vontades entre o particular e o funcionário, mas de dois crimes distintos e autonomamente punidos". Embora o reconhecimento da corrupção passiva nas modalidades de aceitar ou receber implique na configuração da correspondente corrupção ativa, no plano processual "essa (bilateralidade), que é fático-jurídica, depende da produção da prova da autoria correspondente" (BITENCOURT, 2016, p. 124).

\title{
2. O conceito de funcionário público no âmbito Penal e a projeção funcionalista sistêmica sobre o conceito
}

No âmbito penal, o artigo 327 do Código Penal conceitua funcionário público como aquele que "embora transitoriamente ou sem remuneração, exerce cargo, emprego ou função pública" e, em seu parágrafo primeiro equipara a funcionário público "quem exerce cargo, emprego ou função em entidade paraestatal, e quem trabalha para empresa prestadora de serviço 
contratada ou conveniada para a execução de atividade típica da Administração Pública". Portanto, considera-se funcionário público todos aqueles que possuem vinculação profissional com a Administração Pública, ainda que em caráter temporário ou sem remuneração.

No âmbito das convenções internacionais que se produziam sobre o tema, a Convenção Interamericana contra a Corrupção (OEA) define, em seu artigo $1^{\circ}$, como função pública "toda atividade, temporária ou permanente, remunerada ou honorária realizada por uma pessoa física em nome do Estado ou a serviço do Estado ou de suas entidades, em qualquer de seus níveis hierárquicos" e como "funcionário público", "funcionário de governo" ou "servidor público" "qualquer funcionário ou empregado de um Estado ou de suas entidades, inclusive os que tenham sido selecionados, nomeados ou eleitos para desempenhar atividades ou funções em nome do Estado ou a serviço do Estado em qualquer de seus níveis hierárquicos”. No mesmo sentido, a Convenção de Mérida, em seu artigo 2, define funcionário público como:

i) toda pessoa que ocupe um cargo legislativo, executivo, administrativo ou judicial de um Estado Parte, já designado ou empossado, permanente ou temporário, remunerado ou honorário, seja qual for o tempo dessa pessoa no cargo;

ii) toda pessoa que desempenhe uma função pública, inclusive em um organismo público ou numa empresa pública, ou que preste um serviço público, segundo definido na legislação interna do Estado Parte e se aplique na esfera pertinente do ordenamento jurídico desse Estado Parte;

iii) toda pessoa definida como "funcionário público" na legislação interna de um Estado Parte. Não obstante, aos efeitos de algumas medidas específicas incluídas no Capítulo II da presente Convenção, poderá entender-se por "funcionário público" toda pessoa que desempenhe uma função pública ou preste um serviço público segundo definido na legislação interna do Estado Parte e se aplique na esfera pertinente do ordenamento jurídico desse Estado Parte.

Já a Convenção de Palermo, no âmbito da caracterização da corrupção como infração penal, define, em seu Artigo 8, como agente público, além do funcionário público, “qualquer pessoa que preste um serviço público, tal como a expressão é definida no direito interno e aplicada no direito penal do Estado Parte onde a pessoa em questão exerce as suas funções”.

Da comparação entre os instrumentos normativos internos e internacionais, verifica-se, de fato, que há uma ampliação do conceito de funcionário público, consoante às demandas de expansão razoável dentro do espectro de demandas por proteção jurídico-penal. Contudo, face às exigências racionais e irracionais de intervenção jurídico penal, cabe à ciência jurídico-penal perseverar na busca de conceitos que sejam capazes de conhecer a identidade da sociedade e compreendê-la, bem como que constituam modelos sociais legítimos (JAKOBS, 2003b). 
Portanto, para além da compreensão normativa e doutrinária sobre o conceito de funcionário público, faz-se necessária a projeção funcionalista sistêmica sobre o tema para que seja possível a compreensão do alcance do delito de corrupção passiva e dos limites da responsabilização penal do funcionário público.

\subsection{Projeção funcionalista sistêmica sobre o conceito de funcionário público.}

Para a compreensão do delito de corrupção passiva desde uma perspectiva funcionalista sistêmica, faz-se necessário o delineamento da definição de pessoa em direito penal e as formas de comunicação da norma desenvolvidos por Günther Jakobs.

O conceito de pessoa em Jakobs tem suas raízes na Filosofia do Direito de Hegel: "sê pessoa e respeita aos demais como pessoas". Ser pessoa para Jakobs (2003d, p. 30) "significa ter de representar um papel. Pessoa é a máscara, vale dizer, precisamente não é a expressão da subjetividade de seu portador, ao contrário, é a representação de uma competência socialmente compreensível". Assim, a pessoa em direito é definida a partir da função ou do papel que exerce na sociedade. "Dizendo de outro modo, os atores e os demais intervenientes não se tomam como indivíduos com intenções e preferências altamente diversas, mas como aquilo que devem ser a partir do ponto de vista do Direito: como pessoas" (JAKOBS, 2003d, p. 33).

Para Jakobs, o direito penal não lida com sujeitos, mas sim com Pessoa; ou seja, com portadores de funções, sendo que "a função cuja observação garante o Direito Penal é a de cidadão fiel ao Direito; vale dizer, a da pessoa em Direito" (JAKOBS, 2003d, p. 42). Contudo, é importante destacar que a imputação objetiva, no que se refere à imputação penal, não tem como finalidade exclusiva a garantia do cumprimento dos papéis. "A questão especificamente penal da imputação reside unicamente na limitação das tarefas e, em consequência, da responsabilidade a um âmbito delimitado" (JAKOBS, 2003d, p. 34-35).

Posto que trata de pessoas e não de sujeitos, "a partir da perspectiva funcional os conhecimentos atuais do sujeito carecem da importância que lhe concede a dogmática tradicional, naturalista e apegada ao ato psíquico" (JAKOBS, 2003d, p. 34-35). Portanto, somente deve ser reconhecido o alcance do dever segundo o respectivo papel (JAKOBS, 2003b, 
p. 37).

Toda pessoa tem o dever de não praticar nenhum injusto, contudo

o Direito Penal garante a expectativa de que quem está submetido ao direito não vai se comportar de modo culpável, o que significa que será suficientemente fiel ao direito, e, em caso de não mostrar uma fidelidade adequada, isso é de sua responsabilidade, vale dizer, sua culpabilidade, e não do erro de quem tem uma expectativa (JAKOBS, 2003b, p. 37).

Ainda, "a responsabilidade pode provir de como existe socialmente a pessoa responsável” (JAKOBS, 2003c, p. 47). Embora no direito existam obrigações originárias, existem aqueles que se encontram especialmente obrigados (JAKOBS, 2003a). Em razão do Estado ser portador da obrigação, na pessoa dos titulares de uma função pública, de "velar pela satisfação das pretensões penais e pela decisão da autoridade sobre conflitos jurídicos" (JAKOBS, 2003a, p. 34), a violação de deveres que derivam da competência organizacional caracteriza-se por fundamentos jurídicos especiais (JAKOBS, 2003a).

Portanto, o direito penal garante que os portadores de papéis especiais, como por exemplo o funcionário público, "satisfaça, o papel geral de cidadão fiel ao direito e que, como tal, não assumam funções especiais para as quais não estejam preparados e conduzam com cuidado a função assumida" (JAKOBS, 2003b, p. 40).

A responsabilidade jurídico-penal advém, portanto, não no sentido naturalista, "mas pela lesão dos deveres que resultam da competência por organização" (...), pois "ninguém responde em sua condição de Homem, e sim todos na de Pessoas" (JAKOBS, 2003a, p. 45). Sendo assim, a imputação penal deve buscar

\footnotetext{
"fundamentos jurídicos especiais" de deveres que sejam equivalentes aos deveres em virtude de uma competência por organização: a busca não tem de dirigir-se a um "domínio do fato" parecido à organização - isto desorientaria igualmente ao que desorientou a busca, no século XIX, de uma causalidade equivalente à da comissão-, porém tem de dirigir-se àquelas instituições que determinam a identidade da Sociedade da mesma maneira que esta se encontra determinada pelo sinalagma liberdade de organização/responsabilidade pelas consequências (JAKOBS, 2003a, p. 45-46).
}

A projeção funcionalista sistêmica sobre o delito de corrupção sugere, portanto, que a imputação penal do funcionário público deve ser fundamentada na violação de seu papel especial. Em outras palavras, o funcionário público somente pode responder dentro de seu dever 
especial, ou seja na medida do descumprimento de seus deveres especiais especificados no seu rol de deveres enquanto ocupante de função pública. Além da tipicidade e da ilicitude, deve ser analisada, ainda, a reprovabilidade do ato; ou seja, além de típica e ilícita, a conduta deve ser culpável. Assim, para que seja demonstrada a culpabilidade no crime de corrupção passiva impõe-se que ocorra comprovação do ato que efetivamente beneficiaria o agente, pois "a medida segundo a qual se determina a culpabilidade é uma medida completamente objetiva" (JAKOBS, 2003b, p. 42).

Ademais, para Jakobs (2003d, p. 44) “o Direito Penal não se desenvolve na consciência individual, mas na comunicação". Por lidar com pessoas, tal comunicação é pessoal. Na comunicação pessoal, "o outro é algo mais que o objeto de um cálculo estratégico, é um igual, uma pessoa em Direito" (JAKOBS, 2003d, p. 46). Esse reconhecimento como igual consiste numa adscrição, pois todo aquele que negue sua racionalidade ou "estabeleça sua própria identidade de forma excessivamente independente das condições de uma comunidade jurídica já não pode ser tratado razoavelmente como pessoa em Direito" (JAKOBS, 2003d, p. 46).

Portanto, para Jakobs, o delito é uma "falha de comunicação, sendo imputada essa falha ao autor como culpa sua" (JAKOBS, 2003d, p. 4). "A sociedade é a construção de um contexto de comunicação" (JAKOBS, 2003d, p. 10) e "sem processo de comunicação não se geram sujeitos livres" (JAKOBS, 2003d, p. 17). Portanto, há que se desmistificar a concepção de que o direito penal é hostil ao sujeito.

Ademais, para Jakobs, a sociedade e, consequentemente, o direito penal de cada sociedade são normativos: "visto que se trata da configuração, e não da constatação de um estado, a identidade da sociedade se determina por meio das regras de configuração, vale dizer, por meio de normas e não por meio de determinados estados ou bens" (JAKOBS, 2003d, p. 1011). Nesse sentido, “o Direito Penal restabelece no plano da comunicação a vigência perturbada da norma cada vez que se leva a cabo seriamente um procedimento como consequência de uma infração da norma" (...) e "com isso se representa a identidade não modificada da sociedade" (JAKOBS, 2003d, p. 4-5). Nessa perspectiva, “o funcionalismo jurídico-penal se concebe como aquela teoria segundo a qual o Direito Penal está orientado a garantir a identidade normativa, a garantir a constituição da sociedade" (JAKOBS, 2003d, p. 1). 
Jakobs identifica que se a sociedade esta imersa numa tendência de redução dos direitos de liberdade, isso não é exclusividade do direito penal. A decisão de um processo de criminalização excessiva ou desnecessária é questão puramente política e não jurídico-penal. Para o autor, de fato, a Ciência do Direito Penal pode evidenciar as novas regulamentações e o que deve ser valorado. "Mas é impotente perante as alterações políticas de valores, e não se pode optar em favor das alterações políticas de valor" (JAKOBS, 2003d, p. 24).

Portanto, no âmbito do funcionalismo jurídico-penal,

Somente se a ação se entende não como elemento natural, no âmbito da imputação, e sim como conceito que, por sua vez, tenha se determinado pela imputação, a ação se converterá no que deve ser: uma tomada de postura relevante no plano da comunicação, uma expressão de sentido comunicativo relevante (JAKOBS, 2003c, p. 59).

Desse modo, há que se analisar o que a norma sobre corrupção passiva pretende comunicar, pois, embora seja evidentemente um delito complexo - envolvendo necessariamente mais de um agente, bem como a comunicação entre a esfera pública e privada, a ordem econômica, a violação de direitos coletivos e difusos que orbitam a própria concepção de cidadania, integrando complexamente pelo menos os sistemas jurídico, econômico, nacional e internacional, entre outros - sua abordagem deve carregar consigo razões jurídicas fundamentadas em fenômenos jurídico-penalmente relevantes. Ou seja, é necessário que a imputação penal encontre justificativa no âmbito da dogmática jurídico-penal.

Segundo Jakobs (2003b), são exigências do direito penal na atualidade a garantia da expectativa de que quem está submetido ao direito será suficientemente fiel ao direito; especialmente na sociedade marcada pelos contatos anônimos. Soma-se a isso o fato da sociedade atual ainda ser marcada pela sociedade de massas, nas quais os comportamentos se produzem com repetição cotidiana e cada vez mais frequentemente e, com isso, "por meio da massificação de pequenos danos a infraestrutura perde certamente a estabilidade de modo considerável (JAKOBS, 2003b, p.46). Ainda, a sociedade atual é marcada pela imposição do sistema econômico sobre os demais (JAKOBS, 2003b). Assim, torna-se necessário o olhar sobre os problemas específicos da sociedade de massas, especialmente quando observamos o impacto dos delitos à ordem econômica e financeira. Contudo, como ensina Jakobs, a fidelidade ao direito deve ser determinado por meio de parâmetros objetivos e mediante uma pretensão 
dirigida ao conceito de pessoa em direito penal.

\section{Conceito de funcionário público e critérios de imputação penal por infração de deveres especiais no case analisado}

A análise das denúncias e sentença elencadas teve como enfoque os critérios de imputação do delito de corrupção passiva, a análise do conceito de funcionário público e a compreensão dos critérios de imputação de responsabilidade por deveres especiais.

Quanto aos critérios de imputação do delito de corrupção passiva, verificou-se que ambas as denúncias fundamentaram-se na responsabilidade dos funcionários públicos por: a) praticarem, omitirem ou retardarem atos de ofício; b) aceitarem vantagens ou promessas de vantagens indevidas, para si e para outrem, em razão das funções de alto escalão que ocupavam em empresa estatal; c) infração de deveres funcionais enquanto funcionários públicos; e, por fim, d) em razão da função pública de chefe do Poder Executivo responsável pela nomeação e manutenção de funcionários em cargos de alto escalão em empresa estatal denunciados por delito de corrupção passiva.

Verificou-se que foram considerados como critérios de responsabilização por deveres especiais na primeira denúncia o fato dos funcionários públicos ocuparem posições estratégicas e de direção em empresa estatal; já na segunda denúncia, em razão do denunciado ter ocupado o mais alto cargo do Poder Executivo e por ser líder de agremiação partidária.

Nesse ponto, cabe a primeira ressalva em relação à imputação objetiva dos denunciado.Quanto aos deveres funcionais, verificou-se que as denúncias consideraram que em razão das posições estratégicas ocupadas pelos funcionários públicos de alto escalão da empresa estatal, estes detinham poder suficiente para assumirem o compromisso de manterem-se inertes e anuírem quanto à existência e efetivo funcionamento do Cartel no seio e em desfavor da Estatal. Com isso, segundo as denúncias, verifica-se a admissão dos deveres funcionais de imediatamente informar irregularidades e adotar as providências cabíveis do funcionário público no âmbito de suas atuações funcionais como, notadamente, tomar providências para responsabilizar as integrantes do Cartel. O mesmo dever foi caracterizado em relação ao réu da 
segunda denúncia, em razão de ocupar o mais alto cargo do Poder Executivo. Portanto, verificase, a ampliação do rol de deveres especiais em razão da função pública, pois não apenas é esperado dos funcionários públicos que cumpram suas funções de ofício, mas também, o zelo e a responsabilização da conduta de outros agentes, ainda que não subordinados à função pública.

Assim, verifica-se o segundo ponto de análise dogmática em relação à imputação por corrupção passiva em razão da omissão de dever funcional, quais sejam imediatamente informar irregularidades e adotar as providências cabíveis. Ocorre que a denúncia não aborda qual seriam os critérios e os limites normativos e dogmático da responsabilização penal por infração de deveres especiais. O ponto de maior destaque seria justamente em relação à tomar providências para responsabilizar as integrantes do Cartel. Com isso, surge o questionamento se há aportes normativos e dogmáticos para considerar como obrigação funcional a responsabilização de todos os integrantes do Cartel (funcionários públicos ou executivos) por atos delitivos. Analisando a fundo os conceitos trazidos pelos aportes do funcionalismo sistêmico, verifica-se a uma ampliação do rol de deveres funcionais do agente público; contudo, verifica-se uma ausência de delimitação do contexto de comunicação da norma.

O terceiro ponto de enfoque deve-se à possibilidade de fundamentação da violação de deveres especiais em função da ocupação pública a líder de agremiação partidária trazida pela segunda denúncia. No caso da confirmação de tal hipótese, vislumbra-se uma evidência de ampliação do conceito de funcionário público para além dos critérios normativos demonstrados nos capítulos anteriores, ausência de delimitação do contexto de comunicação da norma.

Em relação à sentença analisada (relativa à segunda denúncia), verificou-se que a imputação de corrupção passiva se deu pelo recebimento de vantagens indevidas em razão do seu cargo em prol de agremiação partidária. Mais a frente, destaca-se a imputação em relação ao delito de corrupção ativa pelo recebimento de propinas em prol de agremiação partidária. Ainda, há a imputação do delito de corrupção passiva em face de executivo da empresa denunciada em razão do oferecimento de vantagens indevidas em prol de agremiação partidária, a qual o presente estudo considerou tratar-se de erro material do juiz. 
Assim, verifica-se que a responsabilização do ex-presidente da república, enquanto funcionário público, se deu por participação ativa (e não por omissão), mediante recebimento de vantagem indevida à agremiação partidária a qual fazia parte e mediante enriquecimento pessoal. Demonstrou-se participação ativa do denunciado ao invés da participação passiva. Nesse ponto, é interessante notar a modificação do entendimento jurisprudencial em relação aos critérios de caracterização do delito de corrupção passiva, que tradicionalmente se referem ao abandono dos deveres inerentes ao cargo público ${ }^{8}$. Notou-se, novamentente, a confirmação da ampliação do conceito de funcionário público na sentença analisada. Em outras palavras, verificou-se o reconhecimento de agentes políticos e de partidos políticos sendo considerados como possuidores de deveres especiais em razão de função pública.

Ademais, o denunciado foi responsabilizado pelo não conhecimento de prejuízos da estatal, bem como pela não reprovação da ação dos funcionários públicos de alto escalão da estatal. Com isso, considerou-se como violação do dever funcional o desconhecimento de prejuízo orçamentário e ausência de reprovação de ações delituosas dos funcionários e de outras ações penais (especialmente a Ação Penal 470 julgada em 2013). Portanto, foram considerados como infração de dever funcional o exercício de um papel relevante no esquema criminoso e a indicação dos nomes dos Diretores ao Conselho de Administração da empresa ${ }^{9}$, confundindose a indicação de nomes aos cargos de direção ao Conselho de Administração da estatal com ações criminosas de solicitar, receber, ou aceitar promessa de vantagem indevida.

Com isso, verifica-se a confirmação da ampliação dos limites da responsabilização penal de funcionário público (entendido enquanto indicação de nomes para ocupação de cargo de direção de pessoas que praticam ações normais/funcionais ou conhecimento de ações criminosas no exercício de função pública) na medida que a mesma ultrapassa o princípio da responsabilidade penal pessoal estampado no artigo $5^{\circ}$, XLV, da Constituição Federal.

Portanto, da análise do case verificou-se o surgimento de questões sensíveis aos limites normativos e dogmáticos da intervenção penal especialmente no que se refere à ampliação do

8 Segundo Jakobs (2003a, p.3), "os delitos de omissão mais antigos do Direito Romano se referiam ao abandono dos deveres do cargo público".

9 Nesse sentido: "Entre as provas produzidas a este respeito nos presentes autos cito sua responsabilidade na indicação e manutenção dos Diretores da Petrobras” (PARANÁ, 2019, p. 164). 
conceito de funcionário público e na ampliação do rol de deveres especiais inerentes à função pública. Embora o presente trabalho não tenha se ocupado da tarefa de analisar a fundo os critérios de imputação penal do delito de corrupção passiva, buscou-se demonstrar os sentidos da ampliação do chamamento do direito penal a regulamentação dos conflitos sociais e seus limites legítimos para fins de funcionamento de uma sociedade livre e pluralista.

\section{Considerações finais}

Para a projeção funcionalista sistêmica sobre o crime de corrupção passiva é necessário partirmos da compreensão que toda função pública guarda em si deveres funcionais inerentes à função ocupada e que o recebimento de vantagem indevida por pessoa que ocupa função pública é conduta tipificada no Código Penal que justifica a intervenção penal. Efetivamente, o liame entre o ato de ofício (praticado por aquele que ocupa função pública, sendo detentor de um papel e de um rol de deveres) e a vantagem indevida se dá justamente em decorrência da função pública, sendo esta última condição sine qua non para a concretização do delito de corrupção passiva.

Verificou-se que as observações extraídas do case em análise não são reflexos da tendência jurídico-normativa e dogmática de ampliação dos âmbitos em que o direito penal é instado a intervir no contexto das transformações sociais características do momento histórico "pós-industrial". Do mesmo modo, não observou-se o sentido de desenvolvimento teórico e científico do direito penal no que se refere às constatações de ampliação do conceito de funcionário público no case analisado. Efetivamente, os discurso jurídico sobre o combate à corrupção e aos delitos econômicos tem ganhado uma nova roupagem que não condiz com o viés funcionalista sistêmico ou racional-teleológico da dogmática jurídico-penal.

A não observação dos limites da imputação penal afasta a observância da dogmática jurídico penal levando a prática judicial à contextos persecutórios incompatíveis com os princípios norteadores do contexto social que gerou o direito penal como o conhecemos na atualidade. Quando analisamos o sentido e a trajetória do direito penal, desde seu surgimento até as discussões dogmáticas mais atuais, observa-se uma tendência ao desenvolvimento do direito penal como uma ordem de liberdade. Portanto, faz-se mister reafirmar os direitos 
humanos fundamentais enquanto conquistas civilizatórias irrenunciáveis e que o direito penal enquanto categoria histórico-jurídica do Estado de Direito tem seu surgimento direcionado à proteção da liberdade individual face ao Estado. Se por um lado o direito penal confirma a identidade social (JAKOBS, 2003d), sua função é a de estabilizar normas que garantem a organização de uma sociedade funcional, sem a qual torna-se escassas as condições de subjetividade; ou, em outras palavras, a aplicação do direito penal contrariamente à sua própria normatividade não garante as expectativas sociais e nem o cumprimento de papéis enquanto cidadãos.

Por fim, insta esclarecer que o enfrentamento à corrupção jamais pode justificar a violação de direitos humanos fundamentais, como tampouco a ordem democrática e os preceitos de política criminal sob pena de abalo da própria estabilização da sociedade.

\section{Referências}

BRASIL. Decreto-lei n ${ }^{\circ}$ 2.848, de 7 de dezembro de 1940. Código Penal. Diário Oficial da União, Rio de Janeiro, 31 dez. 1940. Disponível em: <

http://www.planalto.gov.br/ccivil_03/decreto-lei/del2848compilado.htm >. Acesso em: 27/07/2019.

BITENCOURT, Cezar Roberto. Tratado de Direito Penal: parte especial: crimes contra a administração pública e crimes praticados por prefeitos. 10 ed. rev. e atual. São Paulo: Saraiva, 2016.

ORGANIZAÇÃO DAS NAÇÕES UNIDAS (ONU). Convenção das Nações Unidas contra a Corrupção. 31 de outubro de 2003. Decreto $n^{\circ}$ 5.687, de 31 de janeiro de 2006. Disponível em: < http://www.planalto.gov.br/ccivil_03/_Ato2004-2006/2006/Decreto/D5687.htm >. Acesso em $25 / 07 / 2019$.

ORGANIZAÇÃO DAS NAÇÕES UNIDAS (ONU). Convenção das Nações Unidas contra o Crime Organizado Transnacional. 15 de novembro de 2000. Decreto $\mathrm{n}^{\circ} 5.015$, de 12 de março de 2004. Disponível em: < http://www.planalto.gov.br/ccivil_03/_ato20042006/2004/decreto/d5015.htm >. Acesso em 25/07/2019.

ORGANIZAÇÃO DOS ESTADOS AMERICANOS (OEA). Convenção Interamericana contra a Corrupção. 29 de março de 1996. Decreto n ${ }^{\circ} 4.410$, de 7 de outubro de 2002. Disponível em: < http://www.planalto.gov.br/ccivil 03/decreto/2002/D4410.htm >. Acesso em 25/07/2019. 
ORGANIZAÇÃO PARA A COOPERAÇÃO ECONÔMICA E DESENVOLVIMENTO (OCDE). Convenção sobre o Combate da Corrupção de Funcionários Públicos

Estrangeiros em Transações Comerciais Internacionais. 17 de dezembro de 1997. Decreto n 3.678 de 30 de novembro de 2000. Disponível em: <

http://www.planalto.gov.br/ccivil_03/decreto/D3678.htm >. Acesso em 25/07/2019.

JAKOBS, Günther. A imputação penal da ação e da omissão; trad. Maurício Antônio Ribeiro Lopes. Barueri, São Paulo: Manole, 2003a. Estudos de direito penal. v. 7.

; Ciência do direito; e, Ciência do direito penal; trad. Maurício Antônio Ribeiro Lopes. Barueri, São Paulo: Manole, 2003b. Estudos de direito penal. v. 1.

; Fundamentos do direito penal; trad. de André Luís Callegari; colaboração Lúcia Kalil. São Paulo: Editora Revista dos Tribunais, 2003c.

; Sociedade, norma e pessoa: teoria de um direito penal funcional; trad. Maurício Antônio Ribeiro Lopes. Barueri, São Paulo: Manole, 2003d. Estudos de direito penal. v. 6.

MINISTÉRIO PÚBLICO FEDERAL. PROCURADORIA DA REPÚBLICA NO PARANÁ. Distribuição por dependência aos autos no 5006617-29.2016.4.04.7000/PR. Deltan Martinazzo Dallagnol. 22 de maio de 2017. Denúncia. 168. Disponível em: < http://www.mpf.mp.br/grandes-casos/caso-lava-jato/atuacao-na-1ainstancia/parana/denuncias-do-mpf/documentos/Denuncialulasitio.pdf $>$. Acesso em 20/07/2019.

; Distribuição por dependência aos autos no 5049557-14.2013.404.7000 (IPL originário), 5071379-25.2014.4.04.7000 (IPL referente à Odebrecht), 502425172.2015.404.7000. Deltan Martinazzo Dallagnol. 16 de outubro de 2015. Denúncia 137. Disponível em: < http://www.mpf.mp.br/grandes-casos/caso-lava-jato/atuacao-na-1ainstancia/parana/denuncias-do-mpf/documentos/denuncia-mo-36 >. Acesso em 20/07/2019.

PARANÁ. Justiça Federal. 13 ${ }^{\text {a }}$ Vara Federal de Curitiba. Ação Penal no 5021365 32.2017.4.04.7000/PR. Autores: Petróleo Brasileiro S/A - Petrobrás; Ministério Público Federal. Réus: Emilio Alves Odebrecht; Paulo Roberto Valente Gordilho; Luiz Inacio Lula Da Silva; Rogerio Aurelio Pimentel; Alexandrino De Salles Ramos De Alencar; Jose Adelmario Pinheiro Filho; Carlos Armando Guedes Paschoal; Marcelo Bahia Odebrecht; Emyr Diniz Costa Junior; Roberto Teixeira; Agenor Franklin Magalhaes Medeiros; Fernando Bittar; Jose Carlos Costa Marques Bumlai. Juiz Sérgio Fernando Moro. 06 de fevereiro de 2019. Disponível em: < http://www.mpf.mp.br/grandes-casos/caso-lava-jato/atuacao-na-1ainstancia/parana/denuncias-do-mpf/documentos/sentenca-sitio-1 >. Acesso em 20/07/2019.

SILVA SÁNCHEZ, Jesús-Maria. La expansión del derecho penal: aspectos de la política criminal en las sociedades postindustriales. 2. ed. rev. y ampl. Madrid: Civitas, 2001. 